\title{
Dynamic expression of cell-surface antigens probed with Candida albicans-specific monoclonal antibodies
}

\author{
N. Deslauriers, J. Michaud, B. Carré and C. Léveillée† \\ Author for correspondence: N. Deslauriers. Tel: +1418656 2067. Fax: +1 4186562861 \\ e-mail: Noella.Deslauriers@greb.ulaval.ca
}

Immunology Laboratory, Groupe de Recherche en Ecologie Buccale (GREB), Faculty of Dental Medicine, Université Laval, Québec, Canada G1K 7P4

\begin{abstract}
IgG hybridomas were produced which preferentially reacted with cell-surface antigens of either yeast cells or hyphae of Candida albicans. Four mAbs were used in an immunostaining procedure to follow the expression dynamics of these antigens in media supplemented with glucose or galactose. Yeast cell growth was analysed during the lag phase, the early- and late-exponential phases and the stationary phase, and mycelium formation was analysed between 0.5 and $24 \mathrm{~h}$ induction at $37^{\circ} \mathrm{C}$. It appears that yeast cell-surface antigens $5 \mathrm{C11}$ and 2E11 are expressed throughout all phases of yeast cell growth as well as on young hyphae after up to $1 \mathrm{~h}$ induction. Longer hyphae only faintly react with these two mAbs as they switch to hyphal cell-surface antigens 2G8 and 4E1 after $3 \mathrm{~h}$ induction. The reactivity to $\mathrm{mAbs} 2 \mathrm{G8}$ and 4E1 was induced after a $3 \mathrm{~h}$ temperature shift and was confined to the terminal third of growing mycelia. Growth and hyphae induction in galactose prolonged the reactivity of young hyphae with the two anti-yeast-cell mAbs, whereas the expression of surface antigens 2G8 and 2E11 appeared delayed and desynchronized on hyphae. Whereas a similar reactivity was found with ten ATCC strains of C. albicans, four clinical isolates had a unique pattern of reactivity. Immunoblot analyses of DTT extracts of cell-surface constituents indicated that the antigens were proteinaceous in nature and showed that yeast-cell antigens $5 \mathrm{C11}$ and 2E11 are detected in four bands between 68 and $104 \mathrm{kDa}$, whereas mycelial antigens 4E1 and 2G8 are detected in $117 \mathrm{kDa}$ and $104 \mathrm{kDa}$ bands found in mycelial but not in yeast-cell extracts. Present data support the concept of a dynamic balance in the expression of phase-specific antigens in C. albicans.
\end{abstract}

Keywords: Candida albicans, monoclonal antibody, surface antigen

\section{INTRODUCTION}

Within the genus Candida, Candida albicans is of major medical importance, being the most commonly isolated species from various mucosal surfaces in healthy humans and from infectious sites in patients with candidiasis (Odds, 1988). C. albicans is a dimorphic opportunistic pathogen and may grow as budding yeasts (yeast cells) or filamentous chains (hyphae) depending on environmental conditions. There has been an enormous interest in Candida dimorphism because hyphae formation is believed to be a process of pathological significance (Cutler, 1991), and also because hyphal antigens may serve as specific

† Present address: CHUL, Ste-Foy, Quebec, Canada. markers for $C$. albicans identification and candidiasis diagnosis (Poulain et al., 1985). Cell-surface components expressed differentially in both morphological forms are likely to modulate host-parasite relationships, e.g. adherence to and invasion of host cells, cell signalling and interaction with phagocytes.

The composition of the Candida cell wall has been thoroughly studied over the past decade (reviewed in Garzon et al., 1989), and, more recently, antigenic variations in cell-wall mannoproteins as a function of dimorphism were investigated with polyclonal antibodies and monoclonal antibodies (mAbs) (Chaffin et al., 1988; Hopwood et al., 1986; Poulain et al., 1989; Sundstrom et al., 1988; Li \& Cutler, 1991; Torosantucci et al., 1990; Brawner \& Cutler, 1986; Casanova et al., 1989; Ollert \& 
Calderone, 1990; Smail \& Jones, 1984; Leusch, 1989; Ponton et al., 1993; Sundstrom \& Kenny, 1984; Chardes et al., 1986). Some of these cell-surface antigens appear to be expressed on both yeast-cell and hyphal surfaces (Hopwood et al., 1986; Poulain et al., 1989; Sundstrom et al., 1988; Li \& Cutler, 1991; Torosantucci et al., 1990), others being restricted either to yeast cells (Chaffin et al., 1988; Sundstrom et al., 1988) or to germ tubes (Casanova et al., 1989; Ollert \& Calderone, 1990; Smail \& Jones, 1984; Leusch, 1989; Ponton et al., 1993). In addition to suggesting that cell-surface antigens specific for yeast cells and hyphae may be identified, these studies have shown that these antigens are likely to be expressed dynamically during Candida growth and mycelium formation. Until now, most of the antigens identified appear to be carbohydrate in nature and, consequently, $\mathrm{mAbs}$ are typically IgM. Two reports have described IgG mAbs which react with polypeptides preferentially associated with mycelium-specific cell-wall mannoproteins ( $\mathrm{Li} \&$ Cutler, 1991; Ollert \& Calderone, 1990). As polypeptide antigens are the best choice for the characterization of phase-specific epitopes after cloning and large-scale production, we sought to obtain immunological probes specific for surface antigens. IgG hybridomas were produced against $C$. albicans surface polypeptides, the expression of cell-surface determinants on individual cells was investigated during yeast-cell growth and hyphae formation and the molecular constituents were characterized by immunoblots.

\section{METHODS}

Micro-organisms. C. albicans ATCC strains 32354, 28366, 26555, 11006 and 36803 were purchased from the American Type Culture Collection. C. albicans ATCC strains 36801, 44374, 10231, 44373, 36802, and Candida guilliermondii (ATCC 9390), Candida krusei (Laboratoire de Santé publique du Québec 0052, Canada), Candida parapsilosis, Candida pseudotropicalis, Candida tropicalis (LSPQ 0057) and Candida glabrata were provided by Dr Pierre Auger (Université de Montréal, Canada). C. albicans strain LAM-1 was isolated from a case of systemic candidiasis and identified at the Hôpital du St-Sacrement, Quebec City, Canada (Lacasse et al., 1990). Four strains of C. albicans were isolated from patients with Candida-associated denture stomatitis by $\mathrm{Dr}$ R. Pérusse (Faculty of Dental Medicine, Université Laval, Canada) and identified in our laboratory. Stock cultures were grown in liquid Sabouraud medium and aliquots were stored at $-70{ }^{\circ} \mathrm{C}$ in $50 \%$ (v/v) glycerol.

Culture conditions and growth curves. Frozen aliquots of Candida were thawed and cultured in Iscove's modified Dulbecco medium (IMDM) ( $\mathrm{pH} 7 \cdot 3$, Sigma) supplemented with glucose $\left(8.5 \mathrm{~g}^{-1}\right)$ for $48 \mathrm{~h}$ in a moderately shaking water bath at $25^{\circ} \mathrm{C}$ to obtain stationary phase yeast cells. These were diluted to $5 \times 10^{6} \mathrm{ml}^{-1}$ in fresh IMDM supplemented with glucose $(69.4 \mathrm{mM}$ final concentration) or galactose $(500 \mathrm{mM})$. For generating growth curves, yeast cells were grown for $4-48 \mathrm{~h}$ at $25^{\circ} \mathrm{C}$ in a shaking water bath. For determining the germination kinetics of $C$. albicans, suspensions were made in prewarmed medium and incubated at $37^{\circ} \mathrm{C}$ for $0.5-24 \mathrm{~h}$ in a shaking water bath.

Antigen preparations. C. albicans 32354 was used as a source of immunogens for cell fusions. Stationary phase yeast cells were prepared as above and mycelial phase organisms were obtained after $4 \mathrm{~h}$ incubation at $37^{\circ} \mathrm{C}$. After washing twice in $0.1 \mathrm{M}$ Tris buffer, $\mathrm{pH} 8 \cdot 1$, outer-cell-wall antigens were extracted in DTT as described by Smail \& Jones (1984) to yield extracts referred to as DTT-Y and DTT-M, respectively. DTT-Y extracts contain exclusively yeast-cell surface antigens, whereas DTT-M extracts contain a mixture of yeast-cell and mycelial antigens because DTT-M extracts are derived from hyphae-bearing yeast cells. The dialysed extracts were filtered before being lyophilized. After the protein content was estimated, extracts (1 $\mathrm{mg}$ protein $\mathrm{ml}^{-1}$ ) were dissolved in Tris buffer and stored at $-70^{\circ} \mathrm{C}$. These extracts were used for immunization and ELISA protocols. For one immunization protocol, washed yeast cells were killed by overnight incubation in $0.5 \%$ formaldehyde in PBS $(0 \cdot 145 \mathrm{M} \mathrm{NaCl}, 0 \cdot 15 \mathrm{M}$ sodium phosphate $)$ at $4{ }^{\circ} \mathrm{C}$. Aliquots $\left(1 \times 10^{8} \mathrm{ml}^{-1}\right)$ were stored at $-20^{\circ} \mathrm{C}$ after thorough washing in PBS.

Production of anti-C. albicans mAbs. BALB/c mice, 6-8 weeks old, were obtained from Charles River Breeding Farms ( $\mathrm{St}$ Constant, Québec, Canada). To obtain the hybridomas described here, two immunization protocols were used. In the first, mice were primed by subcutaneous injection of $100 \mu \mathrm{g}$ DTT-M in complete Freund's adjuvant. Two booster doses were given by intraperitoneal injections of $100 \mu \mathrm{g}$ DTT-M at $15 \mathrm{~d}$ intervals. In the second, mice were primed by intraperitoneal injection with $5 \times 10^{7}$ formalin-killed yeast cells. Two booster doses of $100 \mu \mathrm{g}$ DTT-M were given intraperitoneally at $15 \mathrm{~d}$ intervals. Following both protocols, the mice were sacrificed $3 \mathrm{~d}$ after the third injection. Spleen cells were fused with SP2 mouse myeloma cells and cultured in selective medium using a previously described procedure (Bazin \& Lemieux, 1989). After 11 d growth, supernatants were screened by ELISA for Ig secretion using heavy-chain-specific affinity-purified antibodies (Kirkegaard and Perry Laboratory; KPL) and whole yeast cells or hyphae as coating antigens (see below). Hybridomas were then cloned by limiting dilution and clones were expanded for the production of supernatants and further characterization.

ELISA for anti-Candida reactivity. Hybridoma supernatants were screened by ELISA shortly after fusion and after cloning by limiting dilution. Briefly, 96-well tound bottom plates (Immulon II; Costar) were treated with $50 \mu \mathrm{g}$ poly-L-lysine $\left(1 \mu \mathrm{g} \mathrm{ml}^{-1}\right.$ in $0.1 \mathrm{M} \mathrm{PBS}, \mathrm{pH} \mathrm{7.3)}$ for $2 \mathrm{~h}$ at room temperature and washed thoroughly with PBS. Stationary phase yeast cells and hyphae of $C$. albicans ATCC 32354 prepared as above were suspended in $0 \cdot 1 \mathrm{M}$ PBS, $\mathrm{pH} 5 \cdot 0$, and distributed at $3 \times 10^{5}$ per well and $1 \times 10^{5}$ per well, respectively. Coating proceeded while drying overnight at $4{ }^{\circ} \mathrm{C}$. Plates were blocked with $1 \%(\mathrm{w} / \mathrm{v})$ BSA in PBS and supernatants were added in $50 \mu \mathrm{l}$ aliquots and incubated for $2 \mathrm{~h}$ at $37^{\circ} \mathrm{C}$. Affinity-purified peroxidase-labelled goat anti-mouse IgG (KPL) was used at a 1/1000 dilution in PBS. 2,2'-Azinobis (3-ethylbenzothiazoline-6-sulfonic acid) diammonium salt (KPL) was used as the substrate at $1 \mathrm{mg} \mathrm{ml}^{-1}$ in citrate buffer. The $A_{405}$ values were read after $30 \mathrm{~min}$. PBS $(\mathrm{pH} 7)$ plus Tween $20(0.05 \%)$ was used for the washes between each step. In a series of experiments involving different species of Candida and different strains of $C$. albicans, whole microorganisms were prepared in the same manner for coating the plates. Further characterization of the $\mathrm{mAbs}$ was carried out using $50 \mu \mathrm{l}$ DTT-Y and $50 \mu \mathrm{l}$ DTT-M $\left(1 \mathrm{mg} \mathrm{m}^{-1}\right)$ as coating antigens.

Immunostaining of the Candida cell surface with mAbs on multiwell microscope slides. The wells of multiwell microscope slides (Flow) were filled with a 20-30 $\mu$ l aliquot of $C$. albicans suspensions (yeast cells or hyphae diluted to $5 \times 10^{6} \mathrm{ml}^{-1}$ ) in PBS. Slides were first treated with $0.1 \%$ poly-Llysine in double-distilled water for $15 \mathrm{~min}$ to ensure strong adhesion of the micro-organisms. Samples were slowly 
evaporated by warming the slides at $45^{\circ} \mathrm{C}$. The slides were stored at $-20^{\circ} \mathrm{C}$ or the samples were rehydrated in blocking buffer as follows. Yeast cells were incubated in TBS, $\mathrm{pH} 7 \cdot 5$, supplemented with $18 \%(\mathrm{w} / \mathrm{v})$ glucose, $10 \%(\mathrm{v} / \mathrm{v})$ glycerol, $0.75 \%$ Tween 20 and $2.5 \%(\mathrm{w} / \mathrm{v})$ BSA. Mycelial-phase microorganisms were incubated in TBS supplemented with $0.1 \%$ gelatin (J. T. Baker). Hybridoma supernatants were added in $30 \mu \mathrm{l}$ aliquots and incubation and revelation of bound antibodies proceeded as in the ELISA assays using diaminobenzidine as the substrate. After washing, the slides were counterstained in $1 \%$ $(\mathrm{w} / \mathrm{v})$ toluidine blue in water for $10 \mathrm{~min}$. Micro-organisms were also assayed by immunofluorescence using affinity-purified fluorescein and rhodamine-labelled goat anti-IgG antibodies (Sigma) diluted 1/200 in PBS supplemented with $0.5 \%$ Tween $20,0.25 \%$ gelatin and $1 \% \mathrm{BSA}$. Counterstaining was done in $0.005 \%$ Evans blue. Negative controls were done by omitting each reagent in turn.

SDSPAGE and Western blotting (immunoblotting). SDSPAGE was performed using a minigel system (Bio-Rad) : $150 \mu \mathrm{g}$ volumes of DTT-M extracts were loaded and the electrophoresis was carried out using $7 \cdot 5 \%(\mathrm{w} / \mathrm{v})$ polyacrylamide gels at $100 \mathrm{~V}$ for $90 \mathrm{~min}$. Gels were silver-stained (Ansorge, 1985) or electrophoretically transferred to a $0.45 \mu \mathrm{m}$ nitrocellulose membrane (Bio-Rad) for $60 \mathrm{~min}$ at $100 \mathrm{~V}$ (Towbin et al., 1979). After the transfer, the nitrocellulose membranes were blocked in TBS as described above before being sliced into strips for staining using a three-layer immunoenzymic technique. Strips were incubated in turn with mAbs (crude supernatants), biotin-labelled goat anti-mouse IgG diluted 1/500 (Sigma), biotin-labelled donkey anti-goat IgG diluted 1/500 (BioCan) and streptavidin alkaline phosphatase diluted $1 / 500$ (Cedarlane). Strips were developed for $8 \mathrm{~min}$ in a nitro blue tetrazolium/5-bromo-4-chloro-3indolyl phosphate solution (Gibco). Negative controls included omitting each reagent in turn and positive controls included developing with mAb A2C7 (Stockbine et al., 1984), which reacts with the $C$. albicans enolase (ATCC HB 8397). In preliminary experiments, thymol-sulfuric acid (Gerard, 1990) was used for staining membrane polysaccharides. In two experiments, DTT extracts were submitted to enzymic cleavage before electrophoresis or after protein transfer to a nitrocellulose membrane using a $2 \mathrm{~h}$ proteinase $\mathrm{K}$ treatment or $\mathrm{N}$-glycosidase $\mathrm{F}$ (Boehringer) digestion (Marot-Leblond et al., 1993). Immunoblots were digitally processed after scanning (Ofoto, Apple) to enhance contrast using Photoshop version 2.0 software (Adobe systems).

\section{RESULTS}

\section{Immunoreactivity of four mAbs against Candida spp. yeast cells and $C$. albicans hyphae}

Four IgG clones obtained using two immunization protocols were studied. As the preliminary screening was done with solid-phase whole micro-organisms, $\mathrm{mAbs}$ that reacted with surface determinants were selected. Furthermore, the ELISA screening protocol was designed to detect clones that produced $\mathrm{mAbs}$ which reacted with germ-tube-bearing micro-organisms but not with yeast cells alone (putative germ-tube-specific clones), or whose reactions were much stronger in wells coated with yeast cells than in wells containing hyphae-bearing yeast cells (putative yeast-cell-specific clones). Of the 237 IgGsecreting clones tested, 19 were positive in ELISA using whole $C$. albicans cells (strain ATCC 32354 cells, i.e. the immunogen). Two clones produced after the first immunization protocol (2G8 and 4E1) reacted with the hyphae-bearing yeast cells of seven strains of $C$. albicans but not with $C$. albicans yeast cells alone, nor with yeast cells from the other Candida spp. Two clones produced after the second immunization protocol (5C11 and 2E11) reacted with yeast cells and with hyphae-bearing yeast cells of seven strains of $C$. albicans and with C. guilliermondii and C. tropicalis yeast cells.

When DTT extracts of $C$. albicans (ATCC 32354) yeast cells (DTT-Y) and of hyphae-bearing yeast cells (DTTM) were used as coating antigens, the reactivities of 2G8 and 4E1 were restricted to wells coated with DTT-M extract, indicating that corresponding immunogens were recovered in extracts containing mycelial antigens but not in extracts containing only yeast-cell antigens. $\mathrm{mAbs} 5 \mathrm{C} 11$ and 2E11 reacted in wells coated with both DT'T-M and DTT-Y extracts, indicating that corresponding immunogens were present in both extracts and were thus of yeastcell origin. As expected, the reactions of $\mathrm{mAbs} 5 \mathrm{C} 11$ and 2E11 were much stronger with the DTT-Y extracts than with DTT-M extracts. This suggested that clones 5C11 and 2E11 might be yeast-cell-specific and that clones 2G8 and 4E1 might be hyphae-specific. An immunofluorescent analysis of these mAbs was carried out using these same strains and species. This qualitative study confirmed the ELISA data and supported our hypothesis that clones $5 \mathrm{C} 11$ and 2E11 react preferentially with yeast cells, whereas clones 2G8 and 4E11 react preferentially with hyphae (Fig. 1). Table 1 summarizes the data obtained after screening the $\mathrm{mAbs}$ with eight strains of $C$. albicans and six other Candida species.

\section{Dynamic expression of yeast cell-surface antigens recognized by mAbs}

C. albicans ATCC 32354 yeast cells were cultured in a synthetic medium, and samples corresponding to the lag phase $(4 \mathrm{~h})$, to the early-, middle- and late-exponential phases $(10,16$ and $20 \mathrm{~h}$, respectively) and to the early-and late-stationary phases (24 and $48 \mathrm{~h}$, respectively) were removed. mAbs 5C11 and 2E11 (anti-yeast-cell) reacted with virtually all the yeast cells throughout the entire growth cycle. At the beginning of the exponential phase, young budding yeast cells tended to remain clustered. A small proportion of the aggregated cells in these clusters $(5-20 \%)$ did not react with the mAbs between 10 and $16 \mathrm{~h}$. Subsequently, the cells tended to dissociate and yeast-cell reactivity increased to $100 \%$ (Table 2).

\section{Dynamic expression of mycelial-surface antigens recognized by mAbs}

Hyphae formation by $C$. albicans ATCC 32354 yeast cells was induced by incubation at $37^{\circ} \mathrm{C}$ for increasing periods of time. Throughout the germination process, mother yeast cells retained the cell-surface antigen recognized by mAbs 5C11 and 2E11 (anti-yeast-cell) (Fig. 2a). Hyphae formation started after $1 \mathrm{~h}$ and young hyphae still expressed yeast antigens. After $5 \mathrm{~h}$ induction, longer hyphae no longer reacted with $\mathrm{mAb} 5 \mathrm{C} 11$, whereas reactivity with $\mathrm{mAb} 2 \mathrm{E} 11$ started to decrease and 

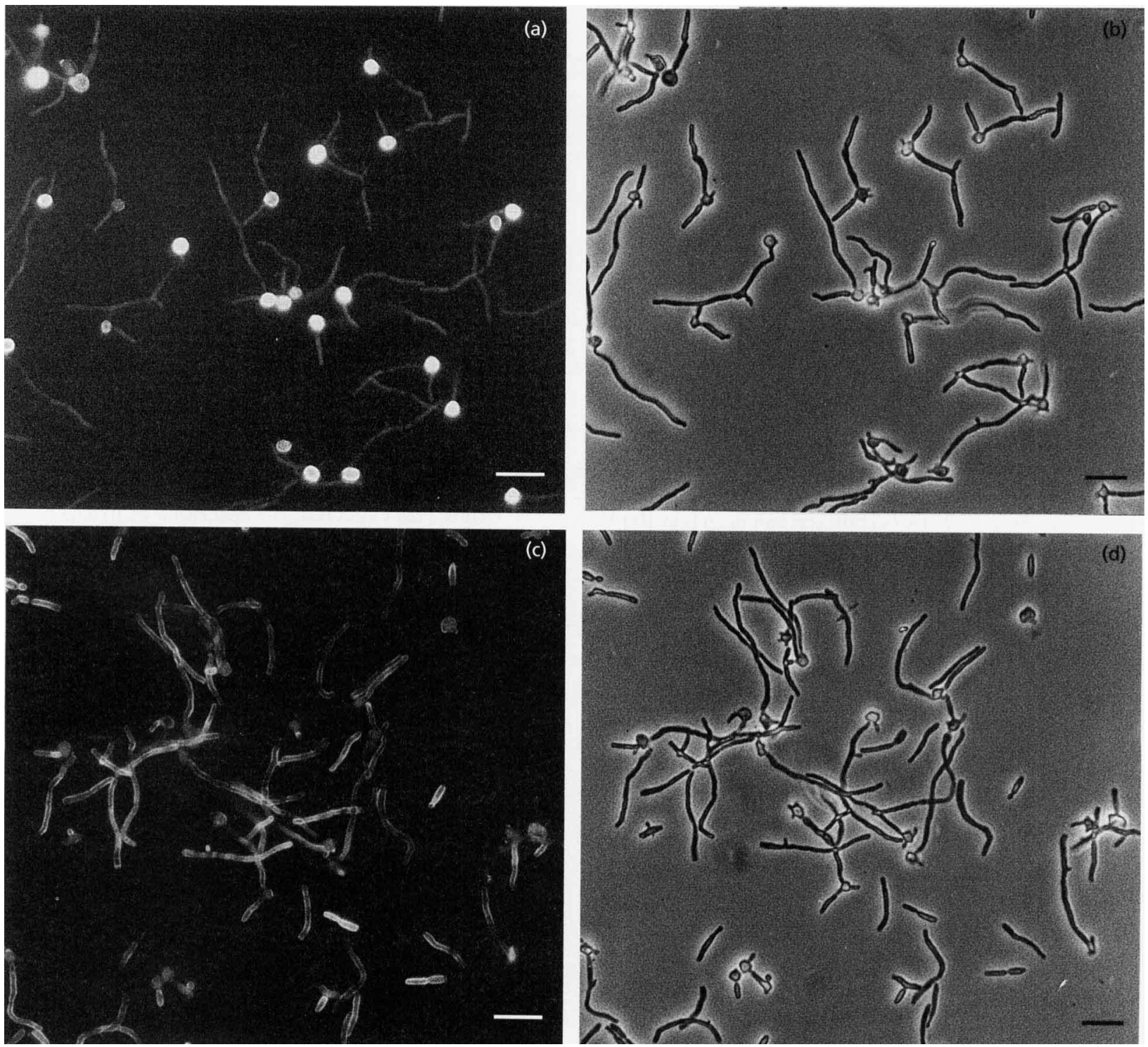

Fig. 1. Immunofluorescent staining of $C$. albicans with mAbs. (a) mAb $5 C 11$ preferentially reacts with $C$. albicans yeast cells. (b) Bright-field illumination of (a). (c) mAb $2 \mathrm{G} 8$ preferentially reacts with $C$ albicans hyphae. Hyphae-bearing yeast cells were harvested after $4 \mathrm{~h}$ induction at $37^{\circ} \mathrm{C}$. (d) Bright-field illumination of (c). Bars, $10 \mu \mathrm{m}$.

disappeared after $24 \mathrm{~h}$ incubation. Anti-mycelium antibodies 2G8 and 4E1 reacted strongly with the entire surface of young hyphae and, thereafter, with the terminal third of the tip of growing mycelia (Fig. 2b, c). Quantitative assessment of the proportion of microorganisms stained with these two mAbs at any time-point suggested that the antigens are expressed synchronously in virtually the entire population throughout the growth kinetics ('Table 2).

\section{Expression of cell-surface antigens in galactose- supplemented medium}

As high concentrations of galactose in defined medium stimulates both the synthesis and immunoreactivity of the fibrillar material, including adhesins, on the Candida cell surface (McCourtie \& Douglas, 1984, 1985; Critchley \& Douglas, 1987), a kinetic study was also carried out in galactose-supplemented medium. mAbs 5C11 and 2E11 (anti-yeast-cell) exhibited the same reactivity with $C$. albicans ATCC 32354 yeast cells under these conditions. However, 2E11 reactivity with young hyphae is conserved longer in galactose-supplemented medium, being observed even after $24 \mathrm{~h}$ induction over the entire surface of growing hyphae. On the other hand, cellsurface structures that react with mAbs $2 \mathrm{G} 8$ and $4 \mathrm{E} 1$ (anti-mycelium) are expressed on a lower proportion of hyphae when germination is induced in medium supplemented with galactose $(<50 \%$ after $6 \mathrm{~h}$ ). Even after $24 \mathrm{~h}$, less than half of the hyphae stained positive with these mAbs. 
Table 1. Reactivity of four mAbs with whole Candida yeast cells and mycelia assayed by immunofluorescence on hyphae-bearing yeast cells

Mycelial induction was at $37^{\circ} \mathrm{C}$ in glucose-supplemented IMDM for $4-6 \mathrm{~h}$. Y, Reactivity with mother yeast cells; $M$, reactivity with growing mycelia.

\begin{tabular}{|c|c|c|c|c|c|c|c|c|}
\hline \multirow[t]{3}{*}{ Candida strain/species } & \multicolumn{8}{|c|}{ mAbs } \\
\hline & \multicolumn{2}{|c|}{$5 \mathrm{C} 11$} & \multicolumn{2}{|c|}{ 2E11 } & \multicolumn{2}{|c|}{$2 \mathrm{G} 8$} & \multicolumn{2}{|c|}{$4 \mathrm{E} 1$} \\
\hline & $\mathbf{Y}$ & $\mathbf{M}$ & $\mathbf{Y}$ & $\mathbf{M}$ & $\mathbf{Y}$ & $\mathbf{M}$ & $\mathbf{Y}$ & $\mathbf{M}$ \\
\hline \multicolumn{9}{|l|}{ C. albicans } \\
\hline ATCC 32354 (serotype A) & + & - & + & - & - & + & - & + \\
\hline ATCC 36801 (serotype A) & + & - & + & - & - & + & - & + \\
\hline ATCC 36802 (serotype B) & + & - & + & - & - & + & - & + \\
\hline ATCC 44373 (serotype B) & + & - & + & - & - & + & - & + \\
\hline ATCC 28366 (serotype unknown) & + & - & + & - & - & + & - & + \\
\hline ATCC 26555 (serotype unknown) & + & - & + & - & - & - & - & - \\
\hline ATCC 36803 (serotype B) & - & - & - & - & - & + & - & + \\
\hline LAM-1 (serotype unknown) & + & - & + & - & - & + & - & + \\
\hline \multicolumn{9}{|l|}{ Other Candida spp. } \\
\hline C. guilliermondii & \multicolumn{2}{|c|}{+} & \multicolumn{2}{|c|}{+} & \multicolumn{2}{|c|}{-} & \multicolumn{2}{|c|}{-} \\
\hline C. psendotropicalis & \multicolumn{2}{|c|}{-} & \multicolumn{2}{|c|}{-} & \multicolumn{2}{|c|}{-} & \multicolumn{2}{|c|}{-} \\
\hline C. tropicalis & \multicolumn{2}{|c|}{+} & \multicolumn{2}{|c|}{+} & \multicolumn{2}{|c|}{-} & \multicolumn{2}{|c|}{-} \\
\hline C. glabrata & \multicolumn{2}{|c|}{-} & \multicolumn{2}{|c|}{-} & \multicolumn{2}{|c|}{-} & \multicolumn{2}{|c|}{ - } \\
\hline C. krusei & \multicolumn{2}{|c|}{-} & \multicolumn{2}{|c|}{-} & \multicolumn{2}{|c|}{-} & \multicolumn{2}{|c|}{-} \\
\hline C. parapsilosis & \multicolumn{2}{|c|}{-} & \multicolumn{2}{|c|}{-} & \multicolumn{2}{|c|}{-} & \multicolumn{2}{|c|}{-} \\
\hline
\end{tabular}

Table 2. Kinetic study of mAb reactivity with C. albicans ATCC 32354 cell-surface antigens

Results shown are a semi-quantitative assessment of the percentage of positive cells:,$\pm \sim 25 \%$; $\sim 50 \% ;++, \sim 75 \% ;+++, 100 \%$. Note that hyphae are not present at the beginning of the kinetics. Y, Reactivity with mother yeast cells; M, reactivity with growing hyphae (mycelia).

\begin{tabular}{|c|c|c|c|c|c|c|c|c|}
\hline \multirow[t]{3}{*}{ Time (h)* } & \multicolumn{8}{|c|}{ mAbs } \\
\hline & \multicolumn{2}{|c|}{$5 \mathrm{C} 11$} & \multicolumn{2}{|c|}{ 2E11 } & \multicolumn{2}{|c|}{$2 \mathrm{G} 8$} & \multicolumn{2}{|c|}{$4 \mathrm{E} 1$} \\
\hline & $\mathbf{Y}$ & $\mathbf{M}$ & $\mathbf{Y}$ & $\mathbf{M}$ & $\mathbf{Y}$ & $\mathbf{M}$ & $\mathbf{Y}$ & $\mathbf{M}$ \\
\hline 0 & +++ & & ++ & & - & & - & \\
\hline 2 & +++ & +++ & +++ & +++ & - & - & - & - \\
\hline 3 & +++ & ++ & +++ & ++ & - & \pm & - & \pm \\
\hline 4 & +++ & \pm & +++ & ++ & - & \pm & - & + \\
\hline 5 & +++ & - & +++ & ++ & - & + & - & ++ \\
\hline 6 & +++ & - & $++t$ & + & - & ++ & - & +++ \\
\hline 24 & +++ & - & +++ & - & - & +++ & - & +++ \\
\hline
\end{tabular}

* Time of mycelial induction at $37^{\circ} \mathrm{C}$ in glucose-supplemented IMDM.

\section{Dynamic expression of cell-surface antigens on various strains of $C$. albicans}

The kinetic study with C. albicans ATCC 32354 was compared to studies of three ATCC strains and four clinical isolates (Table 3). Two out of these three ATCC strains and all the clinical isolates reacted much like $C$. albicans ATCC 32354 with 5C11 (anti-yeast-cell), 2G8 and 4E1 (anti-mycelium). This suggested that the timeregulated expression of the cell-surface antigens defined by these three $m A$ bs may be a feature common to most $C$. albicans isolates. $\mathrm{mAb} 2 \mathrm{E} 11$ had a unique pattern of 

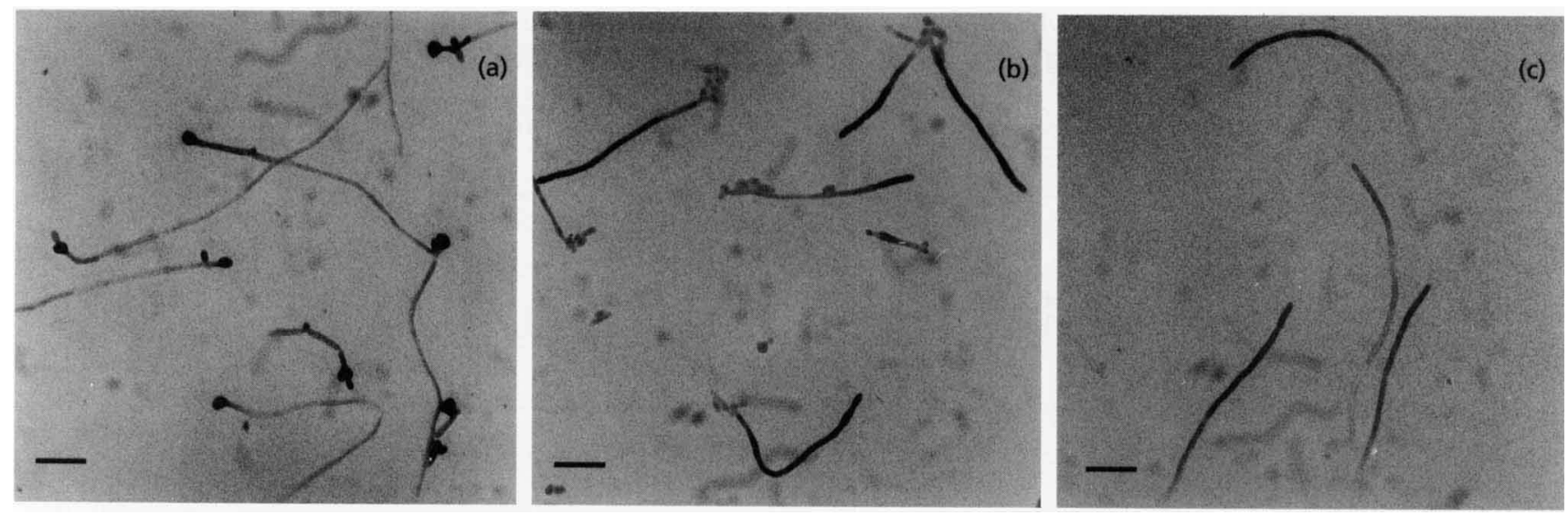

Fig. 2. Immunoenzymic staining of cell-surface antigens on $C$. albicans using mAbs. (a) Reactivity of mother yeast cells with mAb 5C11 (anti-yeast-cells) in the late stage of the germination process (between 5 and $24 \mathrm{~h}$ induction). Parts of some hyphae still faintly react with this $\mathrm{mAb}$. (b) Reactivity of young mycelium ( $3 \mathrm{~h}$ induction) with anti-hyphae mAb 2G8. (c) Reactivity of longer mycelium (5-24 $\mathrm{h}$ induction) with mAb 2G8. Bars, $10 \mu \mathrm{m}$.

Table 3. mAb reactivity with yeast cells and mycelia of various strains of $C$. albicans as shown by immunoenzymic staining

Results shown are a semi-quantitative assessment of the percentage of positive cells:,$- 0 \% ;+$, $<30 \% ;++, 30-60 \% ;+++,>60 \%$. Y, Stationary phase yeast cells grown in glucosesupplemented IMDM; M, hyphae after $24 \mathrm{~h}$ induction at $37^{\circ} \mathrm{C}$ in glucose-supplemented IMDM.

\begin{tabular}{|c|c|c|c|c|c|c|c|c|}
\hline \multirow[t]{3}{*}{ Strains of C. albicans } & \multicolumn{8}{|c|}{$\mathrm{mAbs}$} \\
\hline & \multicolumn{2}{|c|}{5 C11 } & \multicolumn{2}{|c|}{ 2E11 } & \multicolumn{2}{|c|}{$2 G 8$} & \multicolumn{2}{|c|}{$4 \mathrm{E} 1$} \\
\hline & $\mathbf{Y}$ & $\mathbf{M}$ & $\mathbf{Y}$ & $\mathbf{M}$ & $\mathbf{Y}$ & $\mathbf{M}$ & $\mathbf{Y}$ & $\mathbf{M}$ \\
\hline ATCC 32354 & +++ & - & +++ & - & - & +++ & - & $++t$ \\
\hline ATCC 10231 & +++ & - & +++ & - & - & +++ & - & ++ \\
\hline ATCC 36802 & $+t+$ & - & ++ & - & - & +++ & - & +++ \\
\hline ATCC 44374 & - & - & - & - & - & ++ & - & ++ \\
\hline Patient 1 isolate & +++ & - & +++ & +++ & - & +++ & - & +++ \\
\hline Patient 2 isolate & +++ & - & +++ & +++ & - & $+t+$ & - & +++ \\
\hline Patient 3 isolate & +++ & - & +++ & +++ & - & +++ & - & ++ \\
\hline Patient 4 isolate & +++ & - & +++ & +++ & - & + & - & ++ \\
\hline
\end{tabular}

reactivity with the four clinical isolates as over $90 \%$ of hyphae stained along their full length from 7 to $24 \mathrm{~h}$ after induction. This contrasted with the reactivity of this $\mathrm{mAb}$ with the other $C$. albicans strains, which was restricted to yeast cells and to young hyphae (see above), but is reminiscent of the staining pattern obtained using this $\mathrm{mAb}$ with $C$. albicans ATCC 32354 yeast cells grown in galactose-supplemented medium (see above).

\section{Extraction of cell-surface antigens with DTT}

Cell-surface antigens that reacted with the four $\mathrm{mAbs}$ were released following mild extraction with DTT (see above). DT'T-Y and DTT-M extracts no longer reacted with any of the mAbs (data not shown). Under the conditions used, DTT-Y and DTT-M extracts were resolved by SDS-PAGE into approximately 25 major bands as revealed by protein staining (Fig. 3a). Polysaccharides and proteins larger than $200 \mathrm{kDa}$ did not enter the gel. Quantitative differences were observed for most bands resolved from DTT-Y and DTT-M extracts, but the presence of protein bands unique to one or the other extract could not be unambiguously demonstrated.

Attempts to identify the molecular constituents recognized by the $\mathrm{mAbs}$ were made using immunoblots of DTT-M and DTT-Y extracts of C. albicans ATCC 32354. In immunoblots, the yeast-cell antigens 5C11 and 2E11 appeared to be carried by four bands of between 68 
(a)

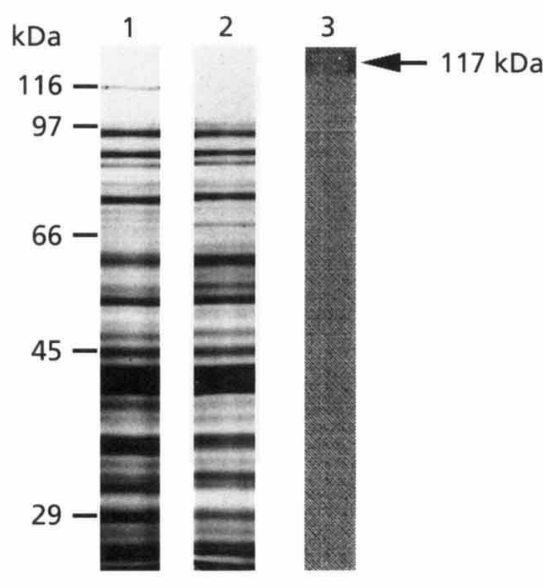

(b)

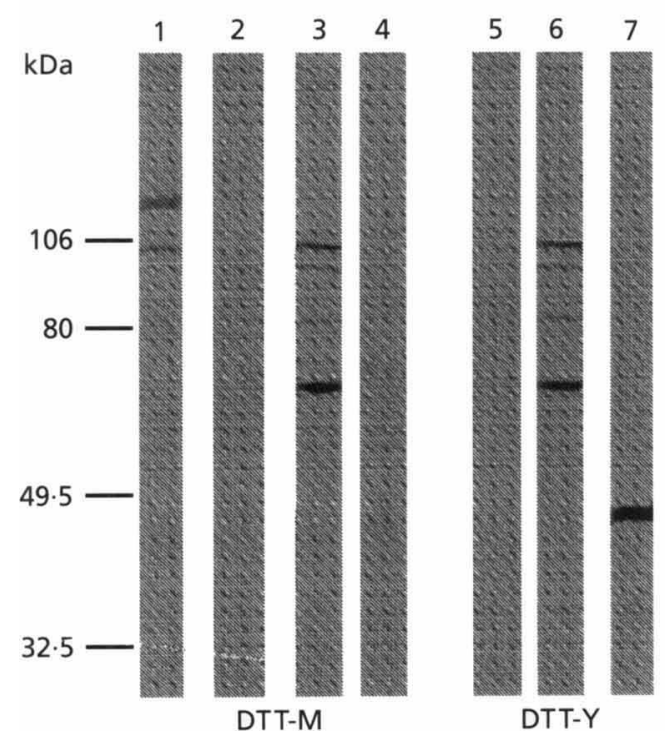

Fig. 3. Immunoblot analysis of $C$. albicans antigens with mAbs. (a) Electrophoretic pattern of DTT-Y (lane 1) and DTT-M (lane 2) extracts after silver staining. Lane 3, electrophoretic pattern of DTT-M extract after thymol-sulfuric acid staining. (b) DTT-M extracts were separated and transferred to nitrocellulose sheets and reacted with $\mathrm{mAb} 4 \mathrm{E} 1$ (lane 1) or mAb 5C11 (lane 3). The same mAbs were used to stain proteinase-K-treated nitrocellulose transfers (lane 2, mAb 4E1; lane 4, mAb 5C11). Treating the membrane with glycosidase before the reaction with the mAb did not change the pattern of lanes 1 and 3. DTT-Y extracts were separated and transferred to nitrocellulose sheets and reacted with mAb $5 \mathrm{C} 11$ before (lane 6) or after (lane 5) proteinase $\mathrm{K}$ treatment of the membrane. Treating the membrane with glycosidase before the reaction with the mAbs did not change the pattern of lane 6. Lane 7, control mAb A2C7 (anti-enolase). Immunoblots were digitally processed after scanning to enhance contrast.

and $104 \mathrm{kDa}$ (Fig. 3b). Similar patterns of reactivity were observed with the two mAbs whether DTT-Y or DTT-M extracts were used, indicating that yeast-cell antigens 5C11 and 2E11 are still present on hyphae-bearing yeast cells and confirming immunostaining data that yeast cells retain their reactivity with $5 \mathrm{C} 11$ and $2 \mathrm{E} 11 \mathrm{mAbs}$ irrespective of their growth cycle and of the germination process. There appeared to be no correlation with the presence in SDS-PAGE of a $117 \mathrm{kDa}$ band found in much higher concentrations in D'T'T-Y extracts than in DT'T-M extracts (Fig. 3a) and the reactivity of the two anti-yeastcell $\mathrm{mAbs}$ with one or the other of the DTT-Y and DTT$M$ extracts (Fig. 3b), since both showed the same pattern of reactivity. On the other hand, the 96 and $82 \mathrm{kDa}$ bands were major components in DTT extracts separated by electrophoresis and silver-stained (Fig. 3a), while the 104 and $68 \mathrm{kDa}$ immunogens detected in immunoblots (Fig. $3 \mathrm{~b}$ ) with both $5 \mathrm{C} 11$ and $2 \mathrm{E} 11 \mathrm{mAbs}$ were only faintly revealed by silver staining (Fig. 3a).

The mycelial antigens 4E1 and 2G8 appeared to be carried predominantly by the 117 and $104 \mathrm{kDa}$ components found in DTT-M extracts (Fig. 3b), but not in DTT-Y extracts. Both $4 \mathrm{E} 1$ and $2 \mathrm{G} 8 \mathrm{mAbs}$ showed the same pattern of reactivity with DTT-M immunoblots and both $\mathrm{mAbs}$ failed to react with DT'T-Y immunoblots. Even though a $117 \mathrm{kDa}$ protein was present at high concentrations in DTT-Y extracts and at very low concentrations in DTT$M$ extracts on SDS-PAGE silver-stained profiles, the reactivity of anti-mycelial $\mathrm{mAbs}$ with DTT-M immunoblots but not with DTT-Y immunoblots suggests that it is independent of this protein component. On the other hand, the $104 \mathrm{kDa}$ immunogen detected by anti-mycelial $\mathrm{mAbs}$ on DT'T-M immunoblots appeared to be absent from DTT-Y immunoblots, even though an immunogen of similar molecular mass is the basis of anti-yeast-cell $\mathrm{mAb} 5 \mathrm{C} 11$ and $2 \mathrm{E} 11$ reactivity.

None of the immunoreactive bands were revealed by polysaccharide staining of the membrane, thymolsulfuric-acid-positive material being confined to the top of the gel ( $>200 \mathrm{kDa}$ ) (Fig. 3b). Glycosidase treatment of the nitrocellulose sheets had no effect, while proteinase $\mathrm{K}$ abolished the reactions with all the mAbs (Fig. $3 \mathrm{~b}$ ).

\section{DISCUSSION}

Four mAbs were analysed by immunostaining, ELISA and immunoblotting for their reactivity with $C$. albicans and other Candida species. Hybridomas were produced and screened to identify $C$. albicans-specific mAbs and phase-specific mAbs, avoiding cross-reactivity with common antigenic structures present in other Candida spp. Mannan is an immunodominant cell-surface antigen (Summers et al., 1964) and C. albicans isolates can be divided into two highly cross-reactive serotypes, designated $A$ and $B$, on the basis of this polysaccharide (Hasenclever \& Mitchell, 1961). C. tropicalis contains cross-reacting antigens as well but appears more closely related to $C$. albicans serotype $A$ than to serotype $B$ (Hasenclever et al., 1961). The specificity of the mAbs that we describe appeared to be serotype-independent and not related to mannan, as suggested by the negative reaction of two strains of $C$. albicans and most other species of Candida. However, anti-yeast-cell $\mathrm{mAbs}$ reacted with a common determinant on nine out of eleven A TCC strains 
of $C$. albicans, four clinical oral C. albicans isolates, one $C$. tropicalis strain and one C. guilliermondii strain. A similar pattern of reactivity of polyclonal antibodies and $\mathrm{mAbs}$ with $C$. albicans, $C$. guilliermondii and $C$. tropicalis, but not with C. krusei, C. parapsilosis and C. glabrata, was reported by other groups (Chaffin et al., 1988; Miyakawa et al., 1986; Tsuchiya et al., 1974; Cassone et al., 1988). Even though this panel of species does not correspond to any of the major Candida groups in the serological classification scheme of Tsuchiya et al. (1974), these pathogenic species may possess common epitopes. However, this does not imply that the same antigenic determinant is involved, as discussed by Chaffin et al. (1988). In fact, carbohydrate epitopes were proposed as recognition structures for the aforementioned antibodies, whereas peptidic epitopes are probably involved in reactions with our $\mathrm{mAbs}$. In any case, this particular pattern of reactivity restricts their specificity to a narrow range of surface antigens that deserves further attention.

When intact organisms are treated with DTT, a complex array of proteins, glycoproteins and polysaccharides is extracted and the surface of the micro-organisms appears roughened (reviewed in Jones, 1989). Such treatment abolished the reactivity of whole yeast cells with $\mathrm{mAbs}$ 5C11 and 2E11, the antigens being recovered in the DT'T soluble extracts. That the two anti-yeast-cell $\mathrm{mAbs}$ shared the same pattern in immunoblots while 2E11 reacted more strongly with growing hyphae (older than $7 \mathrm{~h}$ induction), especially in galactose-supplemented medium, and with mycelia from clinical isolates suggests that these two $\mathrm{mAbs}$ recognized different epitopes on a common protein or that their affinity for a common epitope was different. It is possible that the expression of antigens 2E11 and 5C11 would not be restricted to yeast cells but rather would be quantitatively different on the mycelial surface.

On the other hand, the two mAbs $(2 \mathrm{G} 8,4 \mathrm{E} 1)$ that have a similar reactivity with hyphae appear to detect a mycelium-specific antigen as no reaction was ever observed with yeast cells from $C$. albicans or any other Candida sp. by immunofluorescent/immunoenzymic staining or in ELISA/immunoblots of DTT-Y extracts. This antigen appeared early during the germination process and persisted on the distal portion of older hyphae. With the exception of strain 44374 , where only $50 \%$ of hyphae reacted with $\mathrm{mAbs} 2 \mathrm{G} 8$ and $4 \mathrm{E} 1$, the antigens were expressed on virtually every germ tube in other strains when grown in glucose-supplemented medium. A high concentration of galactose in defined medium has been shown to stimulate both the synthesis and immunoreactivity of the fibrillar material on the Candida cell surface, including adhesion molecules (McCourtie \& Douglas, 1984, 1985; Critchley \& Douglas, 1987). However, our study shows that the percentage of reactive hyphae was both lowered and delayed, if not abolished, when grown on galactose, suggesting that either a denser mucous layer (Garzon et al., 1989) would hamper the access of relevant epitopes to the $\mathrm{mAbs}$, or the expression of the antigens is downregulated under these culture conditions. It cannot be excluded that the shedding (McCourtie \& Douglas, 1985) of 2G8 and $4 \mathrm{E} 1$ during germ-tube development in galactosesupplemented medium would decrease their density at the cell surface and preclude their detection by immunostaining.

As summarized recently by Ponton $e t$ al. (1993), different types of germ-tube surface antigens have been studied by different groups using polyclonal antisera adsorbed with yeast cells or using mAbs. True germ-tube-specific antigens (type I antigens) appear to be scarce, however, because most hyphae-specific $\mathrm{mAbs}$ also react with either DTT-treated yeast cells (type II antigens) or both yeast cells and germ tubes (type IV antigens). We believe that 2G8 and 4E1 are type I antigens because no reactivity has ever been demonstrated with these mAbs against yeast cells of any Candida strain tested before or after DTT treatment, and because DTT-Y extracts tested negative in ELISA and in immunoblots probed with the $2 \mathrm{G} 8$ and $4 \mathrm{E} 1 \mathrm{mAbs}$. The reactivity of these two $\mathrm{mAbs}$ with determinants found at growing hyphal tips from the early initiation of germination to up to $24-48 \mathrm{~h}$ induction is reminiscent of $\mathrm{mAbs} \mathrm{H} 9$ and $\mathrm{C} 6$ described by Brawner \& Cutler (1986). However, these $\mathrm{mAbs}$ are of the IgM isotype and are thought to be directed against carbohydrate rather than protein antigens expressed continuously or periodically on both yeast cells and hyphae.

The notion of a dynamic balance in the expression of phase-specific antigens, which would be environmentally regulated, is supported by the fact that mycelial antigens are preferentially expressed at the growing tip of hyphae, that anti-yeast-cell mAbs react with emerging hyphae but not with older hyphae and that expression of both mycelial and yeast antigens is modified in galactose-supplemented medium. Moreover, that the expression of yeast-cell antigen 2E11 is retained on the surface of growing hyphae in clinical isolates points to an in vivo correspondence with an in vitro regulated shift. In vivo reactivity of these $\mathrm{mAbs}$ against $C$. albicans was previously tested in our experimental mouse model (Lacasse et al., 1990). Mice were topically infected with $C$. albicans LAM-1 and imprints were taken at the peak of the acute infection for immunofluorescent staining (Lamy et al., 1992). Antigens 5C11, 2E11, 2G8 and 4E11 were expressed within the tissue microenvironment, indicating that the specificity of the $\mathrm{mAbs}$ for probing $C$. albicans under physiological conditions was conserved.

The identity of the antigens inducing phase-specific $\mathrm{mAbs}$ is not known, although efforts have been made to characterize them. Until now, most of the mycelial-phasespecific antigens identified by polyclonal antisera have been found to have molecular masses $\geqslant 155 \mathrm{kDa}$ (Leusch, 1989; Ponton \& Jones, 1985; Sundstrom \& Kenny, 1985), and those identified by mAbs have been found to have an even higher molecular mass $(180-260 \mathrm{kDa})$ (Casanova et al., 1989; Marot-Leblond et al., 1993; Torosantucci et al., 1990; Ponton et al., 1993). Most of these antigens are carbohydrates. Surface proteins with molecular masses between 50 and $68 \mathrm{kDa}$ were detected with germ-tube-specific mAbs (Ollert \& Calderone, 1990; 
Linehan et al., 1988). As our $m A b s 2 G 8$ and $4 \mathrm{E} 1$ recognize 104 and $117 \mathrm{kDa}$ proteins on the surface of mycelial cells, they thus differ from all other mycelial-phase-specific mAbs produced until now. To further characterize and purify the mycelial cell-surface antigens $2 \mathrm{G} 8$ and $4 \mathrm{E} 1$, and also to monitor the differential expression of these antigens in hyphae and yeast cells, cloning of the relevant peptidic epitopes is critical, and immunological probes are invaluable for this purpose. This work is in progress in our laboratory.

\section{ACKNOWLEDGEMENTS}

The technical help of Drs F. Martel and L. Lamy is gratefully acknowledged. The authors wish to thank Gene Bourgeau for editorial assistance. This work was supported by the Medical Research Council (Canada) and the Fond de Recherche Dentaire du Québec.

\section{REFERENCES}

Ansorge, W. (1985). Fast and sensitive detection of protein and DNA bands by treatment with potassium permanganate. $J$ Biochem Biopbys Methods 11, 13-20.

Bazin, R. \& Lemieux, R. (1989). Increased proportion of B-cell hybridomas secreting monoclonal antibodies of desired specificity in cultures containing macrophage-derived hybridoma growth factor (IL-6). J Immunol Methods 116, 245-249.

Brawner, D. L. \& Cutler, J. E. (1986). Variability in expression of cell surface antigens of Candida albicans during morphogenesis. Infect Immun 51, 337-343.

Casanova, M., Gil, M. L., Cardenoso, L., Martinez, J. P. \& Sentandreu, R. (1989). Identification of wall-specific antigens synthesized during germ tube formation by Candida albicans. Infect Immun 57, 262-271.

Cassone, A., Torosantucci, A., Boccanera, M., Pellegreni, G., Palma, G. \& Malavasi, F. (1988). Production and characterization of a monoclonal antibody to a cell surface glucomannoprotein constituent of Candida albicans and other pathogenic Candida species. J Med Microbiol 27, 233-238.

Chaffin, W. L., Skudlarek, J. \& Morrow, K. J. (1988). Variable expression of a surface determinant during proliferation of Candida albicans. Infect Immun 56, 302-309.

Chardes, T., Piecharzyk, M., Cavailles, V., Salhi, S. L., Pau, B. \& Bastide, J. M. (1986). Production and partial characterization of anti-Candida monoclonal antibodies. Ann Inst Pasteur Immunol 137C, 117-125.

Critchley, I. A. \& Douglas, L. J. (1987). Isolation and characterization of an adhesin from Candida albicans. J Gen Microbiol 133, 629-636.

Cutler, J. E. (1991). Putative virulence factors of Candida albicans. Annu Rev Microbiol 45, 187-218.

Garzon, S., Marquis, G., Montplaisir, S., Kurstak, E. \& Benhamou, N. (1989). Antigenic structure of Candida albicans. In Immunology of Fungal Diseases, pp. 3-36. Edited by E. Kurstak. New York: Dekker.

Gerard, C. (1990). Purification of glycoproteins. Methods Enzymol 182, 529-538.

Hasenclever, H. F. \& Mitchell, W. O. (1961). Antigenic studies of Candida. I. Observations of two antigenic groups of Candida albicans. J Bacteriol 82, 570-573.

Hasenclever, H. F., Mitchell, w. O. \& Loewe, J. (1961). Antigenic studies of Candida. II. Antigenic relation of Candida albicans group A and group B to Candida stellatoidea and Candida tropicalis. J Bacteriol 82, 574-577.

Hopwood, U., Poulain, D., Fortier, B., Evans, G. \& Vernes, A. (1986). A monoclonal antibody to a cell wall component of Candida albicans. Infect Immun 54, 222-227.

Jones, J. M. (1989). Humoral immune response to Candida albicans. In Immunology of Fungal Diseases, vol. 47, pp. 375-400. Edited by E. Kurstak. New York: Dekker.

Lacasse, M., Fortier, C., Trudel, L., Collet, A. J. \& Deslauriers, N. (1990). Experimental oral candidosis in the mouse: microbiological and histological aspects. J Oral Pathol Med 19, 136-141.

Lamy, L., Léveillé, C., Fortier, C., Lacasse, M., Rojas, M. P. \& Deslauriers, N. (1992). In situ detection of Candida albicans using oral mucosal imprints. J Microbiol Methods 15, 311-320.

Leusch, H. G. (1989). Detection and characterization of two antigens specific for cell walls of Candida albicans mycelial growth phase. Curr Microbiol 19, 193-198.

Li, R. K. \& Cutler, J. E. (1991). A cell surface/plasma membrane antigen of Candida albicans. J Gen Microbiol 137, 455-464.

Linehan, L., Wadsworth, E. \& Calderone, R. (1988). Candida albicans C3d receptor isolated by using a monoclonal antibody. Infect Immun 56, 1981-1986.

Marot-Leblond, A., Robert, R., Aubry, J., Ezcurra, P. \& Senet, J. M. (1993). Identification and immunochemical characterization of a germ tube specific antigen of Candida albicans. FEMS Immunol Med Microbial 7, 175-186.

McCourtie, J. \& Douglas, L. J. (1984). Relationship between cell surface composition, adherence and virulence of Candida albicans. Infect Immun 45, 6-12.

McCourtie, J. \& Douglas, L. J. (1985). Extracellular polymer of Candida albicans: isolation, analysis and role in adhesion. $J$ Gen Microbiol 131, 495-503.

Miyakawa, Y., Kagaya, K. \& Fukazawa, Y. (1986). Production and characterization of agglutinating monoclonal antibodies against predominant antigenic factors for Candida albicans. Infect Immun 23, 881-886.

Odds, F. C. (1988). Ecology of Candida and epidemiology of candidosis. In Candida and Candidosis, pp. 69-92. Edited by F. C. Odds. London: Baillière Tindall.

Ollert, M. D. \& Calderone, R. A. (1990). A monoclonal antibody that defines a surface antigen on Candida albicans hyphae cross-reacts with blastospore protoplasts. Infect Immun 58, 625-631.

Ponton, J. \& Jones, J. M. (1985). Identification of two germ-tube-specific cell wall antigens of Candida albicans. Infect Immun 54, 864-868.

Ponton, J., Marot-Leblond, A., Ezkurra, P. A., Barturen, B., Robert, R. \& Senet, J. M. (1993). Characterization of Candida albicans cell wall antigens with monoclonal antibodies. Infect Immun 61, 4842-4847.

Poulain, D., Hopwood, U. \& Vernes, A. (1985). Antigenic variability of Candida albicans. Crit Rev Microbiol 12, 223-270.

Poulain, D., Cailliez, J. C. \& Dubremetz, J. F. (1989). Secretion of glycoproteins through the cell wall of Candida albicans. Eur J Cell Biol 50, 94-99.

Smail, E. H. \& Jones, J. M. (1984). Demonstration and solubilization of antigens expressed primarily on the surfaces of Candida albicans germ tubes. Infect Immun 45, 74-81.

Stockbine, N. A., Largen, M. T. \& Buckley, H. R. (1984). Production 
and characterization of three monoclonal antibodies to Candida albicans proteins. Infect Immun 43, 1012-1018.

Summers, D. F., Grollman, A. P. \& Hasenclever, H. F. (1964). Polysaccharide antigen of the Candida cell wall. I Immunol 92, 491-499.

Sundstrom, P. M. \& Kenny, G. E. (1984), Characterization of antigen specific to the surface of germ tubes of Candida albicans by immunofluorescence. Infect Immun 43, 850-855.

Sundstrom, P. M. \& Kenny, G. E. (1985). Enzymatic release of germ tube-specific antigens from cell walls of Candida albicans. Infect Immun 49, 609-614.

Sundstrom, P. M., Tam, M. R., Nichols, E. J. \& Kenny, G. E. (1988).

Antigenic differences in the surface mannoproteins of Candida albicans as revealed by monoclonal antibodies. Infect Immun 56, 601-606.
Torosantucci, A., Boccanera, M., Casalinuovo, I., Pellegrini, G. \& Cassone, A. (1990). Differences in the antigenic expression of immunomodulatory mannoprotein constituents on yeast and mycelial forms of Candida albicans. J Gen Microbiol 136, 1421-1428.

Towbin, H., Staehelin, T. \& Gordon, J. (1979). Electrophoretic transfer of proteins from polyacrylamide gels to nitrocellulose sheets: procedure and some applications. Proc Natl Acad Sci USA 76, 4350-4354.

Tsuchiya, T., Fukazawa, Y., Taguchi, M., Nakase, T. \& Shinoda, T. (1974). Serologic aspects of yeast classification. Mycopathol Mycol Appl 53, 77-91.

Received 8 September 1995; revised 29 November 1995; accepted 18 December 1995. 